\title{
Congenital Syphilis as a Measure of Maternal and Child Healthcare, Brazil
}

\author{
Maria Lusia de Morais Belo Bezerra, Flávia Emília Cavalcante Valença Fernandes, \\ João Paulo de Oliveira Nunes, Solma Lúcia Souto Maior de Araújo Baltar, Karina Perrelli Randau
}

Syphilis is a sexually transmitted infection that has direct adverse effects on maternal and infant health through vertical Treponema pallidum transmission during early pregnancy. We evaluated congenital syphilis as a predictor of the quality of basic maternal and child healthcare in Brazil during 2010-2015. We investigated case rates and correlations with epidemiologic and socioeconomic indicators. We observed rising congenital syphilis incidence rates and increasing syphilis-associated perinatal and infant mortality rates in all regions. Case rates were highest in the Northeast, Southeast, and South, and congenital syphilis infant mortality rates were highest in the Northeast and Southeast. We observed correlations between congenital syphilis rates and infant death, spontaneous abortion (miscarriage), and stillbirth rates. We also noted correlations between rates of stillbirth caused by syphilis and inadequate prenatal care. Our study suggests gaps in basic healthcare for pregnant women and indicates the urgent need for measures to increase early diagnosis and appropriate treatment.

Tn 2012, $\approx 5.6$ million new syphilis cases occurred 1 worldwide (1). Syphilis is a sexually transmitted disease caused by the bacterium Treponema pallidum subspecies pallidum, which belongs to the family Treponemataceae. Syphilis can lead to chronic and systemic infectious disease affecting several organs, including skin and mucous membranes. Contact with genital syphilitic lesions is responsible for $95 \%$ of syphilis cases. Congenital syphilis is vertically transmitted from mother to fetus via the placental route and can cause fetal loss after the first trimester and death of the fetus or neonate. A mother can transmit the disease vertically to her newborn during delivery if she has primary syphilis lesions on her genitalia $(2,3)$. The pathogenic potential of the bacterium is responsible for a wide range of sequelae caused by congenital syphilis (4).

Author affiliations: Universidade Federal de Pernambuco, Recife, Brazil (M.L.M.B. Bezerra, F.E.C.V. Fernandes,

S.L.S.M.A. Baltar, K.P. Randau); Universidade Federal de Alagoas, Arapiraca, Brazil (J.P.O. Nunes).

DOI: https://doi.org/10.3201/eid2508.180298
Global epidemiologic data show $T$. pallidum caused $\approx 930,000$ maternal infections in 2012, which led to 350,000 adverse pregnancy outcomes, including 143,000 early fetal deaths and stillbirths, 62,000 neonatal deaths, 44,000 preterm or low birthweight neonates, and 102,000 infections in infants worldwide (5). Progress toward elimination of maternal and congenital syphilis was observed during 20082012. Despite improvements, syphilis continues to affect a high number of pregnant women, causing high rates of perinatal illness and death (5). Elimination efforts are hindered further by a global shortage of benzathine penicillin $\mathrm{G}$, a drug indicated for congenital syphilis prevention (6).

Countries in the Americas have experienced high rates of syphilis and congenital syphilis. Latin America and the Caribbean have demonstrated high syphilis prevalence among pregnant women (7), which contributes to substantial stillbirth rates (8). Recent data indicate that congenital syphilis rates in South America, excluding Brazil, have been stable since 2009, but Brazil has seen increasing case rates (up to $1.7 / 1,000$ live births) that have raised the congenital syphilis rates for the continent. However, each country uses its own case definition for congenital syphilis surveillance, sometimes excluding stillbirths caused by syphilis (syphilitic stillbirths), which makes it difficult to monitor congenital syphilis case rates in the Americas (9).

In Brazil, Ordinance No. 542 made congenital syphilis a mandatory notifiable disease as of December 22, 1986 (10). Maternal syphilis, however, was not included in the national compulsory notification list until July 14, 2005, through Ordinance No. 33 (11). Epidemiologic surveillance demonstrates increased rates of reported congenital syphilis and deaths; infant mortality rates from syphilis increased from 2.4/100,000 live births in 2005 to 7.4/100,000 live births in 2015 (12). The Brazilian Ministry of Health attributes higher maternal syphilis rates to improved epidemiologic surveillance methods and expanded distribution of rapid syphilis tests. Ordinance No. 1,459 established the health policy known as the Stork Network in 2011. The Stork Network promotes improved prenatal care, increased availability of rapid syphilis tests, and fiscal subsidies to control both the maternal and congenital forms of the 
disease (12-14). Rapid tests use digital puncture sampling to detect the presence of treponemal antibodies and enable screening and treatment during a clinical visit. Widespread prenatal syphilis testing improved maternal treatment by reducing difficulties in patient follow-up (15) but simultaneously revealed the high syphilis rates in Brazil. However, a study by Cooper et al. demonstrated that this epidemic has not only become established but worsened in the country (16).

Implementation and expansion of the Family Health Strategy (FHS) also was intended to improve maternal and child healthcare. According to 2013 data from the National Health Survey, $53.4 \%$ of households were registered in family health units in Brazil; greatest coverage was seen in the Northeast (64.7\%) and South (56.2\%) and lowest coverage in the Southeast (46.0\%). Expansion of the FHS for quality primary healthcare is essential for syphilis control and elimination $(17,18)$. However, one study demonstrated inequality in healthcare access in municipalities of Brazil, low effectiveness of prenatal coverage by FHS, and no association with congenital syphilis control (19).

In this context, we evaluated congenital syphilis as a predictor for the quality of basic maternal and child healthcare in Brazil during 2010-2015. We assessed case rates by region and their correlation with epidemiologic and socioeconomic indicators.

\section{Methods}

\section{Study Characteristics}

We used a quantitative approach to conduct an ecologic study of aggregated epidemiologic data on syphilis in pregnant women and children. We collected data from the official website of the Department of Sexually Transmissible Diseases, AIDS and Viral Hepatitis of the Secretariat of Health Surveillance of the Ministry of Health in Brazil (http://indicadoressifilis.aids.gov.br). During August-November 2017, we obtained basic syphilis indicators for 6 years, 2010-2015, from the public domain database and assessed annual syphilis rates for 5 regions of Brazil: North, Northeast, Southeast, South, and Midwest. Data for 2016 were not available during the period we collected indicators for this study.

We collected data on all syphilis cases in pregnant women and those in children $<1$ year of age (considered congenital syphilis) that were reported to national surveillance. In Brazil, health professionals from private and public healthcare settings must complete an official epidemiologic reporting and investigation form for case notification and enter the data into the Notification of Injury Information System database of the Unified Health System. For surveillance, Brazil considers a congenital syphilis case in the following situations: live birth of any fetal age, spontaneous abortion (miscarriage) of a fetus, or stillbirth of an infant born to a woman with clinical or serologic evidence of syphilis who was not treated or received inadequate treatment, including lack of partner treatment; a person $<13$ years of age with increasing nontreponemal titers over time, a reactive nontreponemal titer after 6 months of age, reactive treponemal tests after 18 months of age, or a reactive nontreponemal titer higher than those of the mother; an infant or child with clinical, cerebrospinal fluid, or radiologic evidence of syphilis; or microbiologic evidence of T. pallidum in the placenta or umbilical cord, sample lesion, biopsy, or necropsy of a child, spontaneously aborted fetus, or stillborn infant $(12,20)$, as outlined by the Pan American Health Organization (9). We considered spontaneous abortion due to syphilis as gestational loss at $<22$ weeks' gestation or a fetus that weighed $<500 \mathrm{~g}$ from a woman with syphilis who did not receive treatment or received inadequate treatment. We considered syphilitic stillbirth as death of a fetus $\geq 22$ weeks' gestation or fetus that weighed $\geq 500 \mathrm{~g}$ from a woman with syphilis who did not receive treatment or received inadequate treatment $(12,21)$.

\section{Epidemiologic Variables}

We assessed congenital syphilis by using the following variables: syphilis detection rates in pregnant women $/ 1,000$ live births; maternal schooling level; congenital syphilis cases in the absence of prenatal care; congenital syphilis cases from mothers with inadequate maternal treatment; congenital syphilis cases whose maternal partner did not receive treatment and the number of rapid syphilis tests conducted on pregnant women; congenital syphilis detection rates in children $<1$ year of age/1,000 live births; infant death, excluding stillbirths and fetal deaths, due to congenital syphilis in children $<1$ year of age/100,000 live births; spontaneous abortion due to congenital syphilis/100,000 live births; and syphilitic stillbirths/100,000 live births. We considered child death as death between birth and 12 months of age in a live-born child from a mother with syphilis, excluding spontaneous and stillbirth. We excluded data for any given variable if it was ignored or not included on the official notification form.

Because compulsory notification for congenital syphilis has been in effect since 1986, the available database is more established (12). We estimated congenital syphilis incidence rates by considering the number of new cases in children $<1$ year of age by year in a region multiplied by 1,000 and divided by the number of live births to mothers residing in the same region during that year. We used the same formula to calculate detection of maternal syphilis rates. We calculated infant mortality rates, stillbirths, and spontaneous abortions from congenital syphilis by considering the ratio of the number of cases in the region in a given 
year multiplied by 100,000 and the number of live births to mothers residing in that region during the same year.

\section{Socioeconomic Variables}

We correlated congenital syphilis cases with the following socioeconomic variables from 2010, the year of the country's last population census: illiteracy rate, considered for persons $\geq 15$ of age who cannot read or write; Human Development Index (HDI), which is a measurement calculated on the basis of income parameters (Gross Domestic Product), education (years of schooling), and health (life expectancy); Gini Index for family income per capita, which points out differences between the poorest and the richest incomes; and the Social Vulnerability Index (SVI), which is anchored in 3 dimensions: urban infrastructure, human capital, and income and work $(14,22,23)$.

\section{Data Analyses}

We considered annual congenital syphilis rates and rate increases per region, calculated by the difference between the rates recorded in 2010 and 2015, to evaluate the temporal evolution of incidence rates. We applied the Shapiro Wilk test to verify data normality, with data adherence to the normal distribution. We applied a 1-way analysis of variance followed by a Tukey test to calculate the difference between rates, considering year and geographic region, to identify differences in pairs. We conducted a bivariate analysis by using Pearson's correlation test to verify correlations between variables. We considered a 95\% CI and significance level of 5\% for all analyses. We organized the data on an Excel 2007 worksheet (Microsoft, https://www.microsoft. com) and conducted analyses by using Stata 14.0 (StataCorp., LLC, https://www.stata.com) and GraphPad Prism 5.0 (GraphPad Software, Inc., https://www.graphpad.com).

\section{Results}

\section{Evolution of Congenital Syphilis Rates}

We observed a continuous increase in congenital syphilis case rates in the 5 regions of Brazil during 2010-2015. Case rates doubled and, in some cases, tripled (Figure). For each year, the Northeast and Southeast had the highest congenital syphilis case rates at 2.7-6.9/1,000 live births. In 2015 , case rates in the South were consistent with those in the Northeast and Southeast at 6.9/1,000 live births.

We saw a statistically significant increase $(\mathrm{p}<0.001)$ in mean congenital syphilis rates per year, with the highest mean rate recorded in 2015 (5.92/1,000 live births). Congenital syphilis incidence rates increased in every triennium. Mean rates between regions were not statistically significant. We saw the highest congenital syphilis case rates in the Northeast (4.9/1,000 live births) and Southeast (4.85/1,000 live births) (Table 1).

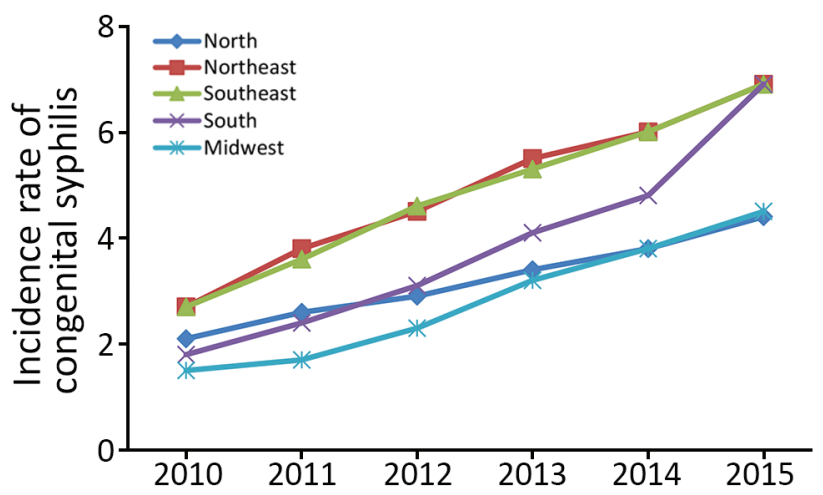

Figure. Incidence rates of congenital syphilis in children $<1$ year of age per 1,000 live births, by year and region, Brazil, 2010-2015.

The mean rates for infant death, spontaneous abortion, and stillbirths per year and region increased during the period we evaluated. We detected statistically significant differences in infant death from congenital syphilis $(p=0.005)$ compared to the mean mortality rate for children $<1$ year of age. We observed a single 3 -year range, 2010-2012, without statistically significant increases in infant mortality rates. We also observed statistically significant differences by region ( $p=0.041)$; the highest mean congenital syphilis infant mortality rates were in the North $(6.27 / 100,000$ live births), Southeast $(5.50 / 100,000)$, and Northeast $(5.28 / 100,000)$. We did not observe statistically significant differences between death rates for the North and Midwest (Table 2).

We did not see statistically significant changes in rates of spontaneous abortion or stillbirth, but we did observe differences by region in the mean spontaneous abortion rates $(\mathrm{p}$ $=0.002)$ and syphilitic stillbirth rates $(\mathrm{p}<0.001)$. The Southeast (20.32/100,000 live births), Northeast $(18.03 / 100,000)$, and South $(15.02 / 100,000)$ had the highest mean spontaneous abortion rates. We also observed the highest stillbirth rates in these regions, with $24.18 / 100,000$ live births in the Northeast, 19.63/100,000 live births in the Southeast, and $12.15 / 100,000$ live births in the South. We observed differences in stillbirth rates between the Northeast and the South, and between the Northeast and the Midwest (Table 3). We saw increases and statistically significant differences $(\mathrm{p}=$ 0.046 ) in mortality rates associated with congenital syphilis, including death of children $<1$ year of age, spontaneous abortion, and stillbirth. We observed high and discrepant ( $\mathrm{p}$ $=0.0007$ ) rates among regions (Table 4).

\section{Variables Correlated with Congenital Syphilis}

We observed positive correlations between incidence of congenital syphilis and maternal syphilis screening $(r=0.688 ; p<0.001)$, infant death due to syphilis $(r=0.679$; $\mathrm{p}<0.001)$, spontaneous abortion due to syphilis $(r=0.859$; $\mathrm{p}<0.001)$, stillbirths due to syphilis $(r=0.829 ; \mathrm{p}<0.001)$, 
Table 1. Mean congenital syphilis case rates in children $<1$ year of age reported to national surveillance, by year and region of Brazil, 2010-2015*

\begin{tabular}{|c|c|c|c|}
\hline Category & $\begin{array}{l}\text { No. cases, } \\
\mathrm{n}=77,414\end{array}$ & Mean rate $(95 \% \mathrm{Cl} \dagger)$ & $p$ value $\ddagger$ \\
\hline \multicolumn{4}{|l|}{ Year } \\
\hline 2010 & 6,944 & $2.16^{\mathrm{a}, \mathrm{b}, \mathrm{c}}(1.67-2.65)$ & \multirow{6}{*}{$<0.001$} \\
\hline 2011 & 9,484 & $2.82^{\mathrm{d}, \mathrm{e}}(2.02-3.62)$ & \\
\hline 2012 & 11,630 & $3.48^{f}(2.55-4.41)$ & \\
\hline 2013 & 13,967 & $4.30^{\mathrm{a}}(3.33-5.27)$ & \\
\hline 2014 & 16,161 & $4.88^{\mathrm{b}, \mathrm{d}}(3.87-5.89)$ & \\
\hline 2015 & 19,228 & $5.92^{\mathrm{c}, \mathrm{e}, \mathrm{f}}(4.69-7.15)$ & \\
\hline \multicolumn{4}{|l|}{ Region } \\
\hline North & 6,055 & $3.20(2.50-3.90)$ & \multirow[t]{5}{*}{0.063} \\
\hline Northeast & 24,597 & $4.90(3.62-6.18)$ & \\
\hline Southeast & 33,699 & $4.85(3.56-6.14)$ & \\
\hline South & 8,974 & $3.85(2.30-5.40)$ & \\
\hline Midwest & 4,089 & $2.83(1.83-3.83)$ & \\
\hline \multicolumn{4}{|c|}{$\begin{array}{l}{ }^{*} \text { Per } 1,000 \text { live births. Values with superscript letters indicate significant } \\
\text { differences between the pairs calculated by using the Tukey test. } \\
\text { †Assuming Poisson distribution. } \\
\ddagger 1 \text {-way analysis of variance; } p<0.05 \text { indicates statistical significance. }\end{array}$} \\
\hline
\end{tabular}

maternal schooling $>8$ years $(\mathrm{r}=0.824 ; \mathrm{p}<0.001)$, and the number of rapid syphilis tests performed in pregnant women $(r=0.519 ; p=0.003)$. We did not observe any correlations in the other variables we investigated (inadequate maternal treatment, untreated maternal partner, no prenatal care), including socioeconomic indicators (illiteracy rate, HDI, Gini index, SVI).

We saw positive correlations between infant mortality, spontaneous abortion, and syphilitic stillbirth rates and maternal schooling $>8$ years and with the number of rapid syphilis test performed in pregnant women. Syphilitic stillbirth rates were the only area in which we saw correlation with lack of prenatal care $(\mathrm{r}=0.613 ; \mathrm{p}<0.001)$, and we did not detect any correlation between these events and socioeconomic indicators (Table 5).

\section{Discussion}

Our study showed continuous increases in congenital syphilis incidence rates in children $<1$ year of age and infant
Table 2. Mean infant mortality rates for congenital syphilis in children $<1$ year of age reported to national surveillance, by year and region of Brazil, 2010-2015*

\begin{tabular}{lccc}
\hline Category & $\begin{array}{c}\text { No. cases, } \\
\mathrm{n}=906\end{array}$ & Mean rate $(95 \% \mathrm{Cl} \dagger)$ & $\mathrm{p}$ value $\neq$ \\
\hline Year & & & \\
2010 & 90 & $2.74^{\mathrm{a}, \mathrm{b}}(1.86-3.62)$ & \\
2011 & 111 & $3.44^{\mathrm{c}}(2.55-4.33)$ & \\
2012 & 147 & $4.22(2.68-5.76)$ & 0.005 \\
2013 & 161 & $5.12(3.37-6.87)$ & \\
2014 & 176 & $6.38^{\mathrm{a}}(4.36-8.40)$ & \\
2015 & 221 & $6.94^{\mathrm{b}, \mathrm{c}}(4.94-8.94)$ & \\
\hline Region & & & \\
North & 119 & $6.27^{\mathrm{d}}(3.77-8.77)$ & \\
Northeast & 265 & $5.28(4.16-6.41)$ & \\
Southeast & 384 & $5.50(4.00-7.00)$ & 0.041 \\
South & 99 & $4.25(2.82-5.68)$ & \\
Midwest & 39 & $2.73^{\mathrm{d}}(1.51-3.96)$ & \\
\hline
\end{tabular}

*Excluding stillbirths and fetal deaths; mean rates/100,000 live births. Values with superscript letters indicate significant differences between the pairs calculated by using the Tukey test.

†Assuming Poisson distribution

$\ddagger 1$-way analysis of variance; $p<0.05$ indicates statistical significance.

death from syphilis during 2010-2015. We also observed increased rates of infant mortality, spontaneous abortion, and syphilitic stillbirth in several regions of Brazil, even with FHS expansion and a greater availability of rapid tests for the early detection of maternal disease.

Rates of primary and secondary syphilis in women are high in Brazil but are not increasing greatly over time (21), suggesting that the high and rising rates of congenital syphilis are due to better detection. New ordinances promoting rapid syphilis testing in pregnancy and better documentation of syphilis in pregnancy and in live and stillborn infants seem to have increased capacity to identify previously unidentified and new cases in Brazil.

Our data indicate that the congenital syphilis incidence rate in 2015 was $>12$ times the reduction target of $<0.5$ cases/1,000 live births for that year, a commitment Brazil assumed along with the Pan American Health Organization and the World Health Organization $(9,24)$. Cooper et al.

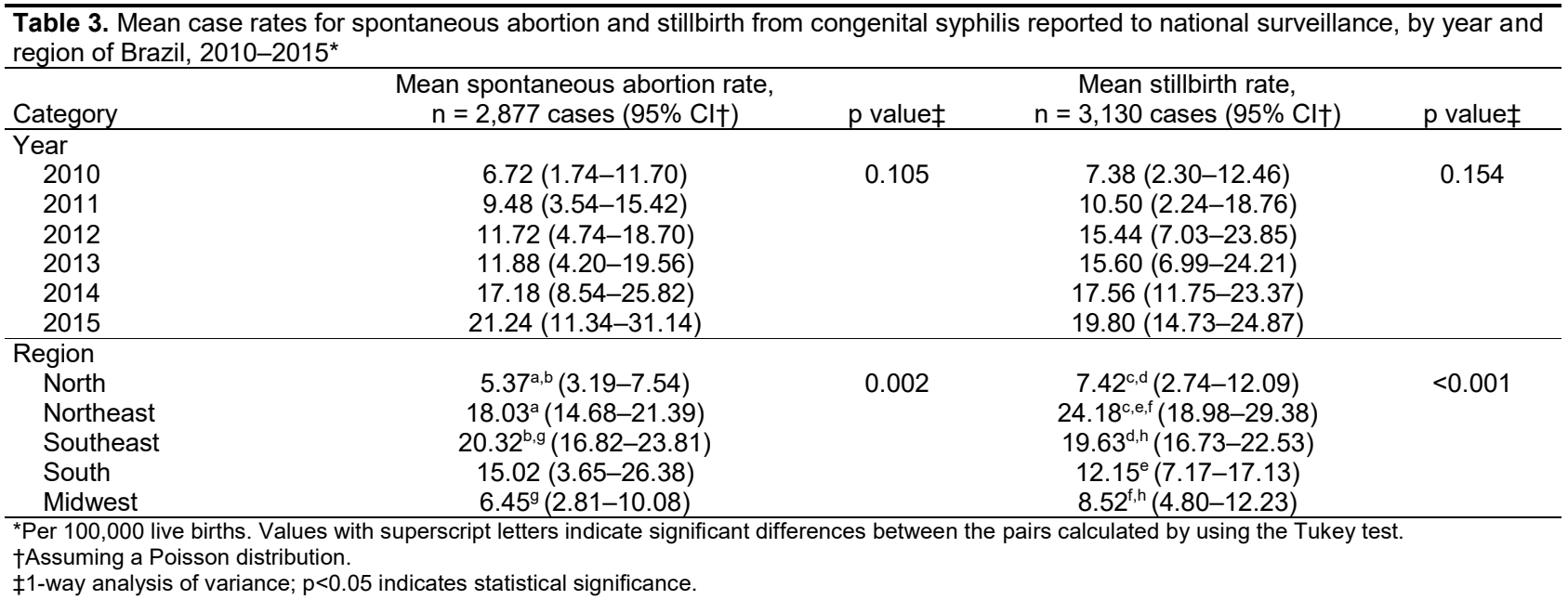


Table 4. Mean rates of death associated with congenital syphilis reported to national surveillance, by year and region of Brazil, 2010-2015*

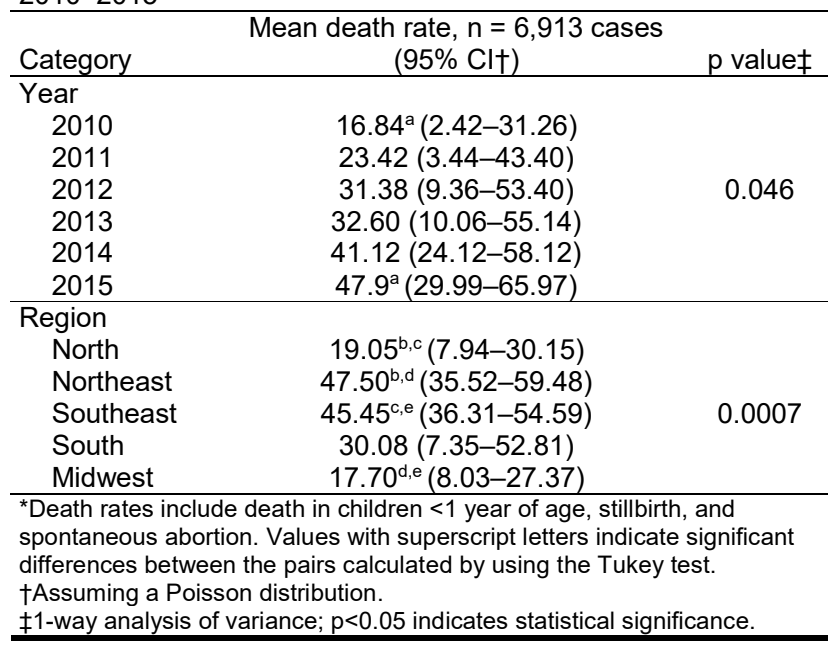

also highlighted this aspect by affirming that Brazil, despite its progress in detecting the disease, has lost its focus toward eliminating congenital syphilis (16).

We saw no correlation between congenital syphilis incidence rates and socioeconomic variables, including illiteracy rate, HDI, Gini index, and SVI, which counters the hypothesis that these factors contribute to the persistence of this disease. A study by Nonato et al. also showed no correlation between congenital syphilis and SVI (25). Data indicate social vulnerability varies between regions of Brazil (23), but we noted that increases in congenital syphilis rates were independent from lower or higher social vulnerability. Low social vulnerability regions, such as the Southeast and South, had high mean congenital syphilis, spontaneous abortion, and stillbirth rates.
However, we also noted high mean rates in high social vulnerability regions. For instance, the North had high infant mortality rates and the Northeast had high mean rates of fetal loss after the first trimester and high mean rates of stillbirth from congenital syphilis.

Congenital syphilis is considered a sentinel event of the quality of prenatal care (26). We saw a correlation between a lack of prenatal care and stillbirth rates due to congenital syphilis. We also saw a correlation between congenital syphilis rates and rates of infant death, spontaneous abortion, and stillbirth. These correlations reinforce the hypothesis that congenital syphilis is a predictor of the quality of prenatal care and reveal the precarious conditions of maternal and child healthcare in Brazil. Adverse outcomes might be related to failure to diagnose or inadequately treat syphilis in pregnant women, which in turn demonstrates fragilities in basic healthcare for mothers and children.

Nonato et al. conducted a study of 353 pregnant women in the state capital of Minas Gerais, in Southeast Brazil, and found a correlation between congenital syphilis and late prenatal care, $<6$ prenatal consultations, and failure to diagnose the disease during the first trimester (25). Our results are further corroborated in a meta-analysis by Qin et al. that found that pregnant women whose syphilis diagnosis and treatment occurred in the first trimester experienced no higher adverse outcomes than women without syphilis (27). In addition, that analysis showed that women whose syphilis was diagnosed and treated in the third trimester had similar adverse pregnancy outcomes to those who did not receive treatment (27).

Increasing access to testing will not reduce congenital syphilis incidence if tests are conducted late in the pregnancy. Even when testing is performed early, adequate treatment is needed to produce a noticeable effect on

\begin{tabular}{|c|c|c|c|c|c|c|c|c|}
\hline \multirow[b]{2}{*}{ Variable } & \multicolumn{2}{|c|}{$\begin{array}{c}\text { Congenital syphilis, } \uparrow \\
n=77,414\end{array}$} & \multicolumn{2}{|c|}{$\begin{array}{l}\text { Infant death, } \neq \\
n=906\end{array}$} & \multicolumn{2}{|c|}{$\begin{array}{l}\text { Fetal death, } \S \\
n=2,877\end{array}$} & \multicolumn{2}{|c|}{$\begin{array}{l}\text { Stillbirth, } \\
n=3,130\end{array}$} \\
\hline & r value\# & $p$ value & r value\# & p value & r value\# & $p$ value & r value\# & $\mathrm{p}$ value \\
\hline Maternal syphilis & 0.688 & $<0.001$ & 0.535 & 0.002 & 0.563 & 0.001 & 0.301 & 0.106 \\
\hline Infant death & 0.679 & $<0.001$ & - & - & 0.439 & 0.015 & 0.523 & 0.003 \\
\hline Fetal death & 0.859 & $<0.001$ & 0.439 & 0.015 & - & - & 0.814 & $<0.001$ \\
\hline Stillbirth & 0.829 & $<0.001$ & 0.523 & 0.003 & 0.814 & $<0.001$ & - & - \\
\hline Maternal schooling $>8 \mathrm{y}$ & 0.824 & $<0.001$ & 0.505 & 0.004 & 0.748 & $<0.001$ & 0.737 & $<0.001$ \\
\hline No prenatal care & 0.305 & 0.101 & 0.132 & 0.486 & 0.360 & 0.051 & 0.613 & $<0.001$ \\
\hline Inadequate maternal treatment & 0.066 & 0.728 & 0.160 & 0.399 & 0.129 & 0.498 & 0.014 & 0.941 \\
\hline Untreated maternal partner & 0.066 & 0.728 & 0.342 & 0.064 & 0.012 & 0.950 & 0.040 & 0.833 \\
\hline Rapid syphilis test of pregnant women & 0.519 & 0.003 & 0.419 & 0.020 & 0.511 & 0.003 & 0.727 & $<0.001$ \\
\hline Illiteracy rates ${ }^{* *}$ & 0.476 & 0.418 & 0.430 & 0.470 & 0.251 & 0.684 & 0.348 & 0.566 \\
\hline Human Development Index ${ }^{\star *}$ & 0.355 & 0.557 & 0.456 & 0.441 & 0.013 & 0.984 & 0.040 & 0.949 \\
\hline Gini Index** & 0.323 & 0.596 & 0.604 & 0.281 & 0.096 & 0.878 & 0.103 & 0.870 \\
\hline Social Vulnerability Index** & 0.467 & 0.426 & 0.627 & 0.256 & 0.172 & 0.781 & 0.193 & 0.754 \\
\hline
\end{tabular}

${ }^{*}$ Bold text indicates statistically significant values $(p<0.05)$.

†Congenital syphilis rates include spontaneous abortion and stillbirth rates.

¥Death in live-born infants from birth through 12 months of age.

$\S$ Fetal death at $<22$ weeks gestation in mothers with positive syphilis seroreactive test results.

IStillborn infants of $\geq 22$ weeks gestation born to mothers with positive syphilis seroreactive test results.

\#Calculated using Pearson correlation coefficient.

**Values from 2010, during the country's last population census. 
congenital syphilis incidence. The high and increasing congenital syphilis rates we recorded might be explained by the inclusion of partner treatment in the congenital syphilis case definition, but it does not explain the higher deaths we noted.

Brazil's Ministry of Health points out that, among mothers of children diagnosed with congenital syphilis in 2015 , a total of $78.4 \%$ sought prenatal care, and $51.4 \%$ of cases were diagnosed. However, more than half of mothers $(56.5 \%)$ received inadequate treatment, and $27.3 \%$ did not have access to treatment (12). Penicillin shortages and resistance of professional health workers to prescribe penicillin during pregnancy likely contributed to the problem. In 2015, only 55\% of the basic health units in Brazil prescribed penicillin to treat syphilis in pregnant mothers. The risk for congenital syphilis increases 5 -fold when maternal partners are infected (28), and $62.3 \%$ of maternal partners did not receive treatment in 2015 (12). Late identification, inadequate management, lack of partner treatment, and incomplete treatment in identified cases are important factors involved in congenital syphilis persistence (26).

According to de la Calle et al., adequate treatment is essential for controlling congenital syphilis (29). The most effective syphilis treatment is benzathine penicillin $\mathrm{G}(6,30,31)$, but despite the medication's efficacy and affordability, syphilis continues to be a public health problem (2). Benzathine penicillin G shortages have compromised treatment for diagnosed syphilis cases in several countries (32), including Brazil (6), which in turn has seen increasing congenital syphilis cases. Countries seeking to expand and improve prenatal care, reduce adverse pregnancy outcomes, and achieve congenital syphilis elimination goals should have access to a steady supply of benzathine penicillin $\mathrm{G}(33)$.

Of note, Brazil experienced increases in congenital syphilis rates before penicillin shortages. We must consider other factors that could be causing these increases, including the quality of prenatal care, resistance or difficulty of pregnant women and their sexual partners to adhere to treatment, and underreporting of the condition $(26,34)$. Cooper et al. (16), as well as several others, indicate that the elimination of maternal and child syphilis transmission can only become a reality in the Americas with implementation and maintenance of clinical excellence in public health services. To reach its goal for eliminating congenital syphilis, Brazil must prioritize congenital syphilis; increase resource allocation to public health; improve syphilis screening in hard-to-reach populations; and invest in organizing health services, professional training, and review of prenatal care procedures, especially for pregnant adolescents $(2,35-38)$.

Our study has some limitations. The data represent aggregated secondary data and, because we analyzed cases together and not individually, we cannot generalize the results. However, a national study demonstrated that estimates for congenital syphilis incidences at birth (3.5/1,000 live births) during 2011-2012 did not differ significantly from those registered by Brazil's Information System for Notifiable Diseases (3.3/1,000 live births) in 2011 (39). Despite this finding, underreporting is a problem in Brazil $(34,40)$. We did not exclude regional variations in case reporting because the quality of the data provided depends on technical and operational conditions of the epidemiologic surveillance system in each region. More worrisome, if underreporting exists, congenital syphilis rates could be even greater than we report.

Our study results indicate that congenital syphilis rates increased in all regions of Brazil during 2010-2015, progressing rapidly and moving the country farther from its target of $<0.5$ cases $/ 1,000$ live births. In addition, high rates of fetal loss after the first trimester and stillbirth rates due to congenital syphilis accentuate the seriousness of this problem. Brazil should prioritize investments in public health, especially for improving prenatal care, with a focus on the early diagnosis of maternal syphilis and strengthening management of benzathine penicillin $G$ treatment to prevent congenital syphilis.

M.L.M.B.B. received financial support from a doctoral scholarship provided by the Federal University of Alagoas Program of Personnel Development, Maceió, Alagoas, Brazil.

\section{About the Author}

Dr. Bezerra is a biologist and professor at the Federal University of Alagoas, Arapiraca, and a PhD student in the Postgraduate Program in Therapeutic Innovation at the Federal University of Pernambuco, Recife, under the advisement of K.P.R. Her research focus is on the epidemiology of sexually transmitted infections and the study of educational strategies for health promotion.

\section{References}

1. Newman L, Rowley J, Vander Hoorn S, Wijesooriya NS, Unemo M, Low N, et al. Global estimates of the prevalence and incidence of four curable sexually transmitted infections in 2012 based on systematic review and global reporting. PLoS One. 2015;10:e0143304. http://dx.doi.org/10.1371/journal.pone.0143304

2. Avelleira JCR, Bottino G. Syphilis: diagnosis, treatment and control [in Portuguese]. An Bras Dermatol. 2006;81:111-26. http://dx.doi.org/10.1590/S0365-05962006000200002

3. Dorado JS, Arellano ER, Pichardo AR, Ezcurra MM. Treponemal infections. Syphilis [in Portuguese]. Medicine-Programa de Formación Médica Continuada Acreditado. 2014;51:2993-3002. https://doi.org/10.1016/S0304-5412(14)70729-2

4. Lago EG, Vaccari A, Fiori RM. Clinical features and follow-up of congenital syphilis. Sex Transm Dis. 2013;40:85-94. http://dx.doi.org/10.1097/OLQ.0b013e31827bd688

5. Wijesooriya NS, Rochat RW, Kamb ML, Turlapati P, Temmerman M, Broutet N, et al. Global burden of maternal and congenital syphilis in 2008 and 2012: a health systems 
modelling study. Lancet Glob Health. 2016;4:e525-33. http://dx.doi.org/10.1016/S2214-109X(16)30135-8

6. Nurse-Findlay S, Taylor MM, Savage M, Mello MB, Saliyou S, Lavayen M, et al. Shortages of benzathine penicillin for prevention of mother-to-child transmission of syphilis: An evaluation from multi-country surveys and stakeholder interviews. PLoS Med. 2017;14:e1002473. http://dx.doi.org/10.1371/ journal.pmed.1002473

7. Schmid GP, Stoner BP, Hawkes S, Broutet N. The need and plan for global elimination of congenital syphilis. Sex Transm Dis. 2007;34(Suppl):S5-10. http://dx.doi.org/10.1097/ 01.olq.0000261456.09797.1b

8. Arnesen L, Martínez G, Mainero L, Serruya S, Durán P. Gestational syphilis and stillbirth in Latin America and the Caribbean. Int J Gynaecol Obstet. 2015;128:241-5. http://dx.doi.org/10.1016/j.ijgo.2014.09.017

9. Pan American Health Organization. Elimination of mother-to-child transmission of HIV and syphilis in the Americas. Update 2016. Washington: The Organization; 2017 [cited 2017 Oct 20]. http://iris.paho.org/xmlui/bitstream/handle/123456789/34072/ 9789275119556-eng.pdf

10. Ordinance no. 542/1986, sect. 1 [in Portuguese]. Official Gazette of the Federative Republic of Brazil. 1986 Dec 24 [cited 2017 Dec 18]. http://www3.crt.saude.sp.gov.br/arquivos/arquivos biblioteca_crt/Portarian542de22dez86.pdf

11. Ordinance MS/SVS no. 33, of July 14, 2005, National list of compulsory notification aggravations [in Portuguese]. Official Gazette of the Federative Republic of Brazil. 2005 Jul 15 [cited 2017 Dec 18]. http://bvsms.saude.gov.br/bvs/saudelegis/svs/2005/ prt0033_14_07_2005.html

12. Brazil Ministry of Health, Secretary of Health Care. Epidemiologic bulletin of syphilis-2016 [in Portuguese]. 2016 [cited 2017 Dec 18]. http://www.aids.gov.br/pt-br/pub/2016/boletimepidemiologico-de-sifilis-2016

13. Brazil Ministry of Health. Ministerial Order No. 1,459 of June 24, 2011, establishing within the scope of the Unified Health System, the Stork Network, sect. 1 [in Portuguese]. 2011 [cited 2017 Dec 18]. http://bvsms.saude.gov.br/bvs/saudelegis/gm/2011/ prt1459 $24 \quad 06 \quad 2011 . h t m l$

14. Institute of Research and Applied Economics. Development in macroregions, Brazil: 2016 [in Portuguese]. Brasília, Brazil: The Institute; 2016 [cited 2017 Nov 9]. http://www.br.undp.org/ content/brazil/pt/home/library/idh/Atlas/macro-regioesbrasileiras.html

15. Benzaken AS, Galbán García E, Sardinha JC, Dutra Junior JC, Peeling R. Rapid tests for diagnosing syphilis: validation in an STD clinic in the Amazon Region, Brazil [in Portuguese]. Cad Saude Publica. 2007;23(Suppl 3):S456-64. http://dx.doi.org/ 10.1590/S0102-311X2007001500013

16. Cooper JM, Michelow IC, Wozniak PS, Sánchez PJ. In time: the persistence of congenital syphilis in Brazil-more progress needed! [in Portuguese]. Rev Paul Pediatr. 2016;34:251-3. http://dx.doi.org/ 10.1016/j.rpped.2016.06.001

17. Malta DC, Santos MAS, Stopa SR, Vieira JEB, Melo EA, Reis C, et al. Family Health Strategy Coverage in Brazil, according to the National Health Survey, 2013 [in Portuguese]. Rev Ciência \& Saúde Coletiva. 2016;2:327-8. http://dx.doi.org/10.1590/ 1413-81232015212.23602015

18. Saraceni V, Miranda AE. Coverage by the Family Health Strategy and diagnosis of syphilis in pregnancy and congenital syphilis [in Portuguese]. Cad Saude Publica. 2012;28:490-6. http://dx.doi.org/ 10.1590/S0102-311X2012000300009

19. Araújo CL, Shimizu HE, Sousa AI, Hamann EM. Incidence of congenital syphilis in Brasil and its relationship with the Family Health Strategy [in Portuguese]. Rev Saude Publica. 2012;46 479-86. http://dx.doi.org/10.1590/S0034-89102012000300010
20. Paz LC, Pereira GF, Pinto VM, Medeiros MG, Matida LH, Saraceni V, et al. New case definition of congenital syphilis for epidemiologic surveillance purposes in Brazil, 2004 [in Portuguese]. Rev Bras Enferm. 2005;58:486-7. http://dx.doi.org/ $10.1590 /$ S0034-71672005000400021

21. Brazil Ministry of Health, Secretary of Health Surveillance, National STD and AIDS Program. Guidelines for the control of congenital syphilis, manual series, 62 [in Portuguese]. 2005 [cited 2017 Dec 19]. http://bvsms.saude.gov.br/bvs/publicacoes/ diretrizes_controle_sifilis_congenita.pdf

22. Brazilian Institute of Geography and Statistics. 2010 Census [in Portuguese] [cited 2017 Nov 7]. https://censo2010.ibge.gov.br

23. Costa MA, Marguti BO, editors. Atlas of social vulnerability in Brazilian municipalities [in Portuguese]. Brasília, Brazil: Institute of Economic and Applied Research; 2015 [cited 2017 Nov 09]. http://ivs.ipea.gov.br/images/publicacoes/Ivs/publicacao_atlas_ ivs.pdf

24. Ministry of Health, Department of Health Surveillance. Guide to surveillance in health [in Portuguese]. 2014 [cited 2018 Jan 17]. http://www.saude.campinas.sp.gov.br/doencas/Guia_VE.pdf

25. Nonato SM, Melo APS, Guimarães MDC. Syphilis in pregnancy and factors associated with congenital syphilis in Belo Horizonte-MG, Brazil, 2010-2013 [in Portuguese]. Epidemiol Serv Saude. 2015;24:681-94. http://dx.doi.org/10.5123/ S1679-49742015000400010

26. Domingues RMSM, Saracen V, Hartz ZMDA, Leal MDC. Congenital syphilis: a sentinel event in antenatal care quality [in Portuguese]. Rev Saude Publica. 2013;47:147-57. http://dx.doi.org/10.1590/S0034-89102013000100019

27. Qin J, Yang T, Xiao S, Tan H, Feng T, Fu H. Reported estimates of adverse pregnancy outcomes among women with and without syphilis: a systematic review and meta-analysis. PLoS One. 2014;9:e102203. http://dx.doi.org/10.1371/journal.pone.0102203

28. Qin JB, Feng TJ, Yang TB, Hong FC, Lan LN, Zhang CL. Maternal and paternal factors associated with congenital syphilis in Shenzhen, China: a prospective cohort study. Eur J Clin Microbiol Infect Dis. 2014;33:221-32. http://dx.doi.org/10.1007/s10096013-1948-Z

29. de la Calle M, Cruceyra M, de Haro M, Magdaleno F, Montero MD, Aracil J, et al. Syphilis and pregnancy: study of 94 cases [in Spanish]. Med Clin (Barc). 2013;141:141-4. http://dx.doi.org/ 10.1016/j.medcli.2012.11.033

30. Rodríguez-Cerdeira C, Silami-Lopes VG. Congenital syphilis in the 21st century [in Spanish]. Actas Dermosifiliogr. 2012;103:679-93. http://dx.doi.org/10.1016/j.adengl.2012.09.003

31. Walker GJA, Walker DG. Congenital syphilis: a continuing but neglected problem. Semin Fetal Neonatal Med. 2007;12:198-206. https://doi.org/10.1016/j.siny.2007.01.019

32. US Centers for Disease Control and Prevention. Bicillin-L-A (benzathine penicillin G) shortage. Atlanta: The Centers; 2016 [cited 2017 Dec 18]

33. Taylor MM, Zhang X, Nurse-Findlay S, Hedman L, Kiarie J. The amount of penicillin needed to prevent mother-to-child transmission of syphilis. Bull World Health Org Suppl. 2016;94:559-A. http://dx.doi.org/10.2471/BLT.16.173310

34. Lafetá KR, Martelli Júnior H, Silveira MF, Paranaíba LM. Maternal and congenital syphilis, underreported and difficult to control [in Portuguese]. Rev Bras Epidemiol. 2016;19:63-74. http://dx.doi.org/10.1590/1980-5497201600010006

35. Gomez GB, Kamb ML, Newman LM, Mark J, Broutet N, Hawkes SJ. Untreated maternal syphilis and adverse outcomes of pregnancy: a systematic review and meta-analysis. Bull World Health Org Suppl. 2013;91:217-26. http://dx.doi.og10.2471/ BLT.12.107623

36. Sabidó M, Benzaken AS, de-Andrade-Rodrigues EJ, Mayaud P. Rapid point-of-care diagnostic test for syphilis in high-risk 
populations, Manaus, Brazil. Emerg Infect Dis. 2009;15:647-9. http://dx.doi.org/10.3201/eid1504.081293

37. Saraceni V, Pereira GFM, da Silveira MF, Araujo MAL,

Miranda AE. Epidemiological surveillance of vertical transmission of syphilis: data from six federal units in Brazil [in Portuguese]. Rev Panam Salud Publica. 2017;41:e44.

38. Vilarinho LM, Nogueira LT, Nagahama EE. Evaluation of quality of health care for adolescents in the prenatal and puerperium [in Portuguese]. Escola Anna Nery Revista de Enfermagem. 2012; 16:312-9.http://dx.doi.org/10.1590/S1414-81452012000200015

39. Domingues RM, Leal MD. Incidence of congenital syphilis and factors associated with vertical transmission: data from the
Birth in Brazil study [in Portuguese]. Cad Saude Publica. 2016;32. http://dx.doi.org/10.1590/0102-311X00082415

40. Carvalho ID, Brito RS. Congenital syphilis in the state of Rio Grande do Norte: a descriptive study in the period 2007-2010 [in Portuguese]. Epidemiol Serv Saude. 2014;23:287-94. http://dx.doi.org/10.5123/S1679-49742014000200010

Address for correspondence: Karina Perrelli Randau, Universidade Federal de Pernambuco, Departamento de Ciências Farmacêuticas, Av Prof Arthur de Sá S/N CDU, Recife-PE CEP:50740-521, Brazil; email:krandau@hotmail.com

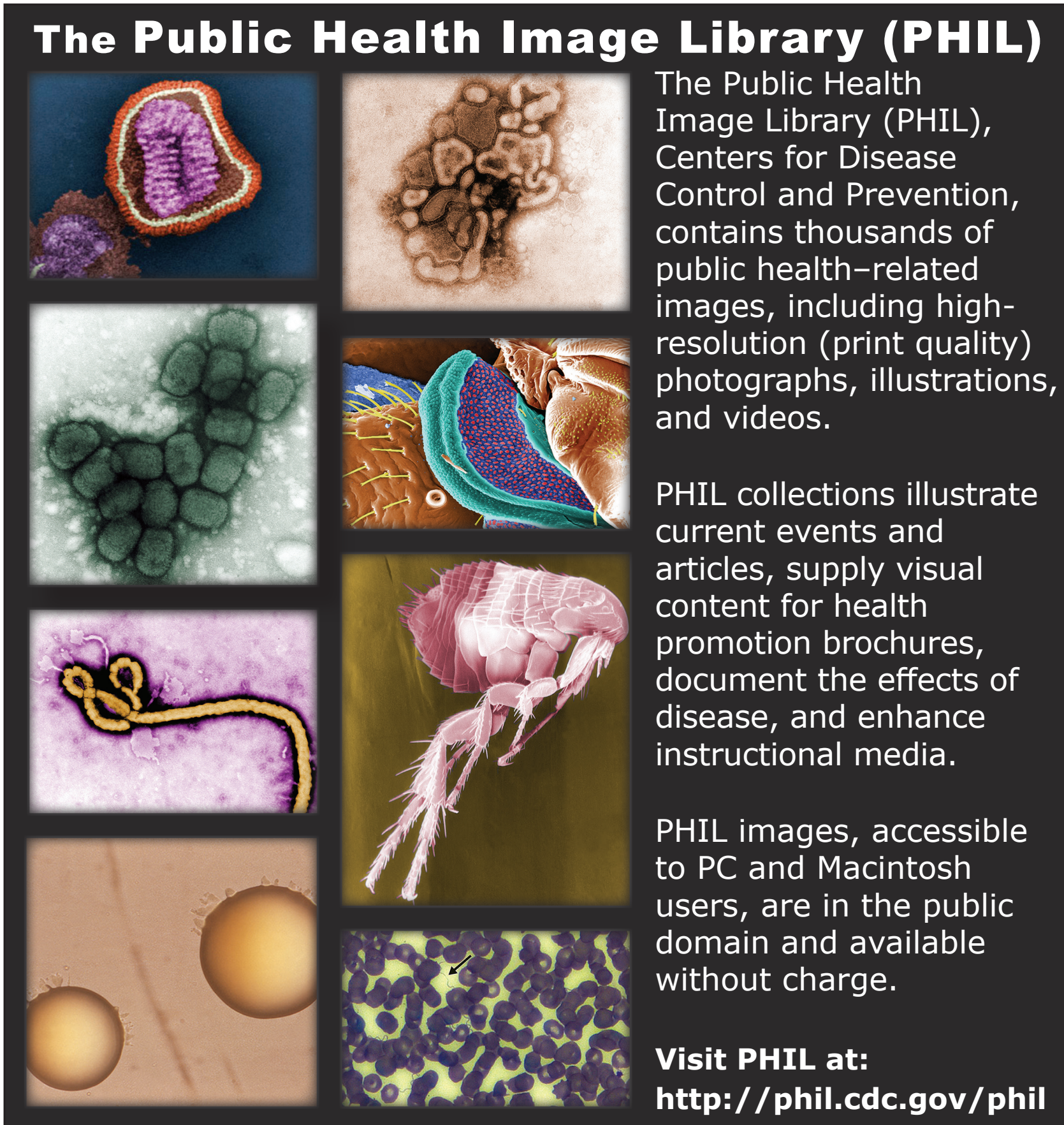

